\title{
BDA website package
}

$\mathrm{T}$ he BDA has organised a website package for dentists available from the BDA's website developers, Synergy Interactive, for $\mathfrak{E} 35$ per month.

More and more people are using the World Wide Web to shop for goods and services, including dental treatment. If you are on the BDA's Find-a-dentist, patients will be able to link from your FAD entry to your website, which will tell them all they need to know about your practice. But Synergy will also register your site with the top 5 UK search engines on the web.

The package includes 25 webpages, a password area for you to change text and will incorporate the BDA's own patient education animations and information, which will be updated regularly by the BDA. The package will be based on 10 different templates, one of which you can view in totality now at:

http://www.support.synergy-interactive.co.uk/wfd/ example/index.html.

For more information contact the BDA on 0171 9350875 and ask about 'Websites for dentists'.

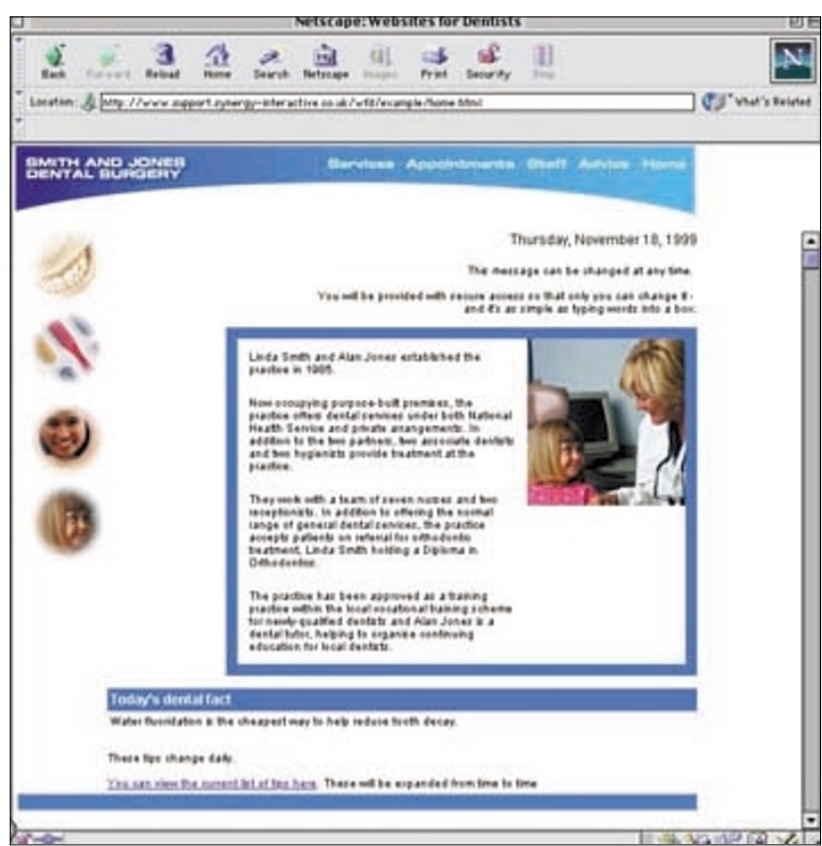

Alternatively you can e-mail a request for information to: v.broome@bda-dentistry.org.uk. 